\title{
Women's Knowledge and Attitude towards Cervical Cancer Preventive Measures and associated factors In South Gondar Zone, Amhara Region, North Central Ethiopia: A Cross-Sectional Study
}

Yilkal Tafere ( $\sim$ yilkal2007@gmail.com )

Debre Markos University

Tezera Jemere

University of Gondar

Tsion Desalegn

Debre Tabor University

Addisu Melak

Debre Tabor University

Research

Keywords: Cervical cancer, Knowledge, attitude

Posted Date: December 18th, 2020

DOl: https://doi.org/10.21203/rs.3.rs-130171/v1

License: (c) (1) This work is licensed under a Creative Commons Attribution 4.0 International License.

Read Full License 


\section{Abstract \\ Background}

The aim of the current research was to assess women's knowledge and attitudes towards cervical cancer preventions in South Gondar zone.

\section{Methods}

A community-based cross-sectional study was carried out in South Gondar zone, Ethiopia. A total of 844 women aged 18 and above have participated in the current study. Binary and multivariable logistic models were used to assess predictors of women's knowledge and attitude towards cervical cancer.

\section{Results}

About $66 \%$ of the women had heard about cervical cancer. The percentage of women who heard about cervical cancer was $66 \%$. Regarding the main source of information of respondents, $75.4 \%$ were heard from health professionals. Sixty two point four percent of women knew at least one preventive measure and $82.6 \%$ of participants knew at least one symptom or sign. Among study participants, $25 \%$ and $64 \%$ had good knowledge, and favorable attitude towards cervical cancer prevention measures, respectively. Being reside in rural $(A O R=.21,95 \% \mathrm{Cl} ; .18, .34)$, not attending formal education $(\mathrm{AOR}=0.50,95 \% \mathrm{Cl}: 0.3$, 0.75), low income (AOR $=.57,95 \% \mathrm{Cl}: .43, .81)$ and having < 4 children $((\mathrm{AOR}=.8,95 \% \mathrm{Cl} . .60-.86)$ were negatively associated with knowledge toward cervical cancer prevention measures

\section{Plain English Summary}

In Ethiopia, Cervical cancer is the most common cause of hospitalization and death among women, often due to late disease stage at diagnosis. Previous evidence has shown that a lack of awareness and unfavorable attitudes towards cervical cancer are considered as barriers to the prevention of cervical cancer. A community-based cross-sectional study was carried out in South Gondar zone, Ethiopia. A total of 844 women responded to the questionnaire which makes a response rate of $100 \%$. About $804(95.7 \%)$ of the respondents were orthodox in religion. The majority of them were $367(43.5 \%)$ were housewives. Nearly half (49.9\%) of the respondents had a monthly income between 1001- 2000 birr.

About $66 \%$ of the women had heard about cervical cancer. The percentage of women who heard about cervical cancer was $66 \%$. Regarding the main source of information of respondents, $75.4 \%$ were heard from health professionals. Sixty two point four percent of women knew at least one preventive measure and $82.6 \%$ of participants knew at least one symptom or sign. Among study participants, $25 \%$ and $64 \%$ had good knowledge, and favorable attitude towards cervical cancer prevention measures, respectively. 
In conclusion; this study found the majority of the respondents had poor knowledge about cervical cancer prevention measures. The majority of the study participants had favorable attitudes regarding cervical cancer prevention. Living in rural areas, not attending any formal education low income and having less than four children was negatively associated with respondents' knowledge towards cervical cancer prevention measures. There is needed to scale up cervical cancer prevention measures and services so that more women can access them irrespective of where they reside.

\section{Background}

Cervical cancer is a type of cancer that occurs in the cells of the cervix; it affects many women worldwide and is caused by Human papillomavirus (HPV) $(1,2)$. The disease can be prevented via, immunization, early detection and prompt treatment of detecting precancerous lesions (3).

Globally; eighty percent of women are living in low-income countries and it is a major health problem among reproductive cancers worldwide $(4,5)$. Globally, the governments of different countries give priority to immunization of women against HPV infection as part of early prevention [1]. Having early sexual intercourse leads a woman to be infected with HPV. Patients of cervical cancer may develop symptoms years after being infected (6).

About $28 \%$ of Cameroonian women had prior knowledge of cervical cancer (7). A study done in Nigeria revealed that $15 \%$ had heard of cervical cancer, overall $40 \%$ of the respondents had poor knowledge of cervical cancer (8). A study conducted in Uganda revealed that $55.4 \%$ of the women had high knowledge about cervical cancer. With regards to a woman's risk of developing cervical cancer: about $78.4 \%$ of respondents stated that a woman might have a risk of developing cervical cancer if women had multiple sexual partners, $88.4 \%$ being infected with the HPV, and $73.9 \%$ respondents thought early sexual intercourse at a young. Nearly $79.2 \%$ of women also assumed that using contraceptives for a long time increased one's risk of developing cancer (9).

Urban residents and higher incomes were associated with the level of knowledge about cervical cancer prevention (9). Study in Kenya suggests that $51 \%$ of the respondents were aware of cervical cancer; Health professionals working in health institutions were used as the major source of awareness for women (10). A study in Mizan Tepi revealed that $33.97 \%$ of the respondents had poor knowledge and only $25.4 \%$ of the respondents had good knowledge. More than half $(61 \%)$ of women had a positive attitude for the early intervention of cervical cancer via screening (11).

In Ethiopia; Patients came for treatment at the late stage of cervical cancer in that no benefit can be obtained from any treatments. Currently, it becomes a major problem for women, as more of them keep on presenting with cervical cancer at a later stage (12). Knowledge and attitude are important in improving the understanding of factors influencing the involvement of women in preventive activities towards cervical cancer. The objective of the study was to assess knowledge, attitude towards cervical cancer prevention measures of women in South Gondar zone, Ethiopia 


\section{Methods}

The Study Setting and population

A community-based cross-sectional study was conducted from August 20 to September $20 / 2019$ in three selected districts of South Gondar zone which is located $105 \mathrm{~km}$ far from Bahir Dar (the capital city of the Amhara region) and about $666 \mathrm{~km}$ northwest from Addis Ababa the capital of Ethiopia. According to the 2007 census result, it has populations of $2,526,813$ of this $1,260,880$ male and 1265933 were female.

The sample size was determined by using a single population proportion. Considering that the proportion of knowledge towards cervical cancer prevention is $50 \%$. For determining the sample size of this study, $5 \%$ level of significance $(a=0.05), 5 \%$ margin of error $(d=0.05)$ and $10 \%$ non-responsive rate and design effect of 2 were taken into account. Based on this, the total sample of the study was determined to be 844

Multi-stage sampling was used, three districts in South Gondar zone was selected by lottery method. Out of the three districts, 15 kebeles (the smallest administrative unit in Ethiopia) were selected by using simple random sampling. House to house census was conducted to know the total population of women aged 18 and above in the selected kebeles. Based on the census result, 844 women were allocated proportionally to each district. Finally, individual women age 18 and above were selected using a systematic sampling technique, women were contacted directly door to door in the community. If the woman was not at home during the visit, two additional attempts were done before declaring not available .Face to face interview was administered by a nurse after explaining the objectives when women were free and in a comfortable condition at their home. Data were collected using structured and pre-tested questioners. The questionnaires were first prepared in English, and translated into the local language (Amharic).

The dependent variable was - Knowledge (good vs. Poor), -Attitude (positive vs. negative). The independent variables were age, marital status, education, religion, ethnicity, occupation Condom use with first sex, no of a partner, number of children

Operational definitions: Good Knowledge: respondents who score $50 \%$ and above of correct responses of knowledge questions, Poor knowledge, respondents with a score of less than $50 \%$ of the correct responses of knowledge questions. Positive attitude: Respondents who scored above the mean and the mean score had a Positive attitude towards prevention for cervical cancer.

Negative attitude: Respondents who scored below the mean score had a negative attitude towards prevention for premalignant cervical cancer.

The data was entered using EP info and analyzed using SPSS version 20 software. Logistic analysis was applied, Odds ratios with $95 \%$ confidence intervals were computed to identify the presence of association and statistical significance is $p<0.05$. 
Ethical clearance was obtained from research evaluation and an ethical review committee of Debre Tabor University College of Health Sciences. Permission letter was also obtained from South Gondar Health department. The participants were informed that participation is made entirely voluntarily and verbal consent was obtained.

\section{Results}

A total of 844 women responded to the questionnaire which makes a response rate of $100 \%$. The mean age of respondents was 30.2 years (Standard Deviation [SD] = 7.3). About $804(95.7 \%)$ of the respondents were orthodox in religion and all (100\%) of the respondents were Amhara in ethnicity. Nearly third quartile $618(73.2 \%)$ of the women were married and the majority of them were $367(43.5 \%)$ were housewives. and most $(499 ; 59.1 \%)$ had attended formal education and the remaining $(345 ; 40.9 \%)$ did not attend any formal education. The majority $(618 ; 73.2 \%)$ of the respondents were married, more than half $(514 ; 60.1 \%)$ of the respondent lives in rural areas. Nearly half $(49.9 \%)$ of the respondents had a monthly income between 1001- 2000 birr (Table 1).

\section{Knowledge about cervical cancer prevention measures}

About two-thirds $(66 \%)$ of the study participants replied that they were aware of cervical cancer prevention measures. Health professionals were nearly the third quartile of the women's sources information. About 59 (10.6\%) of respondents' were used mass media as a source of information. Regarding the prevention and treatment of cervical cancer $120(14.2 \%)$ of respondents reported that primary prevention is crucial, nearly one in ten women were aware of the curability of the disease if it is detected early. Among the respondents, 250 (29.6\%) correctly answered a minimum of one prevention measure of the disease.

One hundred fifty $(17.8 \%)$ respondents knew a minimum of one symptom of cancer. Six $(0.7 \%)$ women responded that having more than one sexual partner, infected with the human papillomavirus (HPV) 8 (1\%), practice early sexual intercourse 54 (6.4\%), and cigarette smoking $170(20 \%)$ increased risk of developing cervical cancer. One in hundreds of women was not aware of the risk factors for cervical cancer. Vaccination $25(3 \%)$, delaying sexual intercourse 68 (8\%), minimize multiple sexual relationships $40(4.7 \%)$, using condom 28 (3.3\%) were mentioned by the women to prevent cervical cancer. Seventy (4\%) of the respondents did not mention any prevention methods. Concerning knowledge of the respondent about signs and symptoms of cervical cancer, vaginal bleeding $110(13.1 \%)$ and vaginal discharge 40 (4.8\%) were known by the women. Overall 212(25.12 \%) of the women had good knowledge about cervical cancer prevention measures (Table 2).

\section{The attitude of respondents towards cervical cancer prevention measures}

Almost half $430(50.1 \%)$ of the respondents believed that they were at risk of developing cervical cancer and nearly half $441(48.1 \%)$ of the respondents agree that Carcinoma of the cervix is highly prevalent in our country and is a leading cause of deaths amongst all malignancies in Ethiopia. More than half 522 
$(61.8 \%)$ of the participants agree that cervical carcinoma cannot be transmitted from person to person while $38.2 \%$ of them agreed it can be transmitted from person to person.

About $607(71.0 \%)$ of the respondents agreed that screening helps to prevent cervical cancer. More than half $544(64.5 \%)$ of respondents perceived that screening causes no harm to the patient, whereas, $35.5 \%$ agrees as it is harmful. In general 539(63.8\%) of the respondents had a favorable attitude towards cervical cancer prevention measures. About 472(59.9\%) of participants thought that screening for premalignant cervical lesions is expensive and 765(90.6\%) of the women were agreed that if screening is free and causes no harm to be screened (Table 3)

Predictors of knowledge of women about cervical cancer prevention measures

Different variables were tested for their association with the knowledge of the women towards cervical cancer prevention measures. Place of Resident, Monthly income, Level of education and Parity of the women were associated with the level of knowledge on cervical cancer in both bivariate and multivariate analysis. One woman was knowledgeable toward cervical cancer prevention measures for every five women who live in rural areas (AOR= $0.21,95 \% \mathrm{Cl} ; .18, .34)$. One woman was knowledgeable toward cervical cancer prevention measures for every two women who were not attending formal education (AOR $=0.50,95 \% \mathrm{Cl}: 0.3,0.75)$

Women having low monthly income $(\mathrm{AOR}=.57,95 \% \mathrm{Cl} .43, .81)$, women having $<4$ children $((\mathrm{AOR}=.8$, $95 \% \mathrm{Cl}$. .60 - .86) were negatively associated with knowledge toward cervical cancer prevention measures compared to their counterpart .An odds ratio for religion and ethnicity of women was not computed as nearly all women belong to Orthodox Christian and all the women are Amhara in their ethnicity (table 4)

\section{Discussion}

The current study demonstrated that $60 \%$ of the participants had heard about cervical cancer. Previous literature has shown that awareness of cervical cancer was found to be $28 \%$ in Cameroon (7), $15 \%$ in Nigeria (8), $51 \%$ in Kenya (10), and $93 \%$ in Ghana (13). The variation might be due to differences in study populations. .A study in Ghana uses study groups were medical students, non-medical undergraduate students, nurses, and senior university staff might have a better understanding of cervical cancer, whereas the current study includes both rural and urban residents, all of them were not health professionals. Subsequently designing appropriate awareness creation mechanisms is crucial to address all women about cervical cancer prevention measures.

In this study, health professionals were used as the main source of information followed by radio or TV. This implies that health professionals have a key role in educating women.

In this study, ten percent of the women were knowledgeable about the capability of being cured of cervical cancer if it is diagnosed early. This knowledge gap might inhibit women from implementing 
cervical cancer prevention measures. Hence health promotion, education, and communication about cervical cancer prevention measures are important.

This study, the finding indicates that nearly a third quartile or (75\%) of the respondents had poor knowledge of cervical cancer prevention measures. In contrast to this finding; recent studies showed that in Mizan Tepi University, Ethiopia nearly 34\% (11) and Uganda, 44.6\% (9) of the respondents had poor knowledge about cervical cancer. University students might have access to different mass-medias that may increase their awareness level towards cervical cancer prevention measures. The current study was conducted at a community level, including the rural areas. Hence the awareness of these women about cervical cancer is minimal; there is a need to educate women on the early warning signs of cervical cancer as failure to recognize the early symptoms and signs contribute to the late presentation common in Ethiopia.

This implies that, in the absence of proper health education strategy in the health system and at a community level, hence tailored health education strategy should be implemented that can help to improve the knowledge of the respondents towards the symptoms of cervical cancer to take measures early.

Concerning the prevention of cervical cancer participants knew that cervical cancer is prevented by avoiding multiple sexual partners (4.7\%), avoiding early sexual intercourse (8\%), and quitting smoking $(10.5 \%)$, vaccination (3\%), using a condom (3.3\%) while in a study done in Sweden $62 \%$ respondents reported that cervical cancer can be prevented by early screening and HPV vaccination (14). This disparity could be related to an early screening and availability of the HPV vaccine and services might be provided in all health care systems in developed nations like Sweden to the population at every facility

The current study indicates that overall $63.8 \%$ of the respondents had a positive attitude towards cervical cancer prevention measures; a similar magnitude of attitude $(61.24 \%)$ is reported from recent studies in Mizan Taipei University, Ethiopia (11). In this study, about $32 \%$ of participants agreed to be screened for cervical cancer if the cost is free and has no harm health check-up, hence avoiding barriers will help in increasing the number of women participants for screening. Awareness creation activities regarding cervical cancer at a grass root level are crucial

In this study, women residing in rural areas, not attending formal education, low-income, parity less than 4 were negatively associated with good knowledge of women for cervical cancer. This is possible because women who were living in urban may have access for health workers that can give health education for their clients; in addition to this; women who attend any formal education may have the ability to read different leaflet and other printed materials that are a key source of information about cervical cancer and its prevention measures. Women that have more than four children might have proximity to the health facilities that provide antenatal care may provide counseling services toward cervical cancer and its prevention measure. Integrating all health services with cervical cancer services would enhance awareness among women. Hence awareness creation activities should be accessible for women who 
reside in rural areas that enhance the knowledge of the women about the disease and prevention measures.

Women who belonged to the lower socioeconomic category were less knowledgeable about cervical cancer prevention compared to those from the high status might have different communication, mass media and this could reflect that the awareness might be increased that could increase the demand to use service-related cervical cancer. Lack of standardized questionnaire to measure the knowledge and attitude of the respondents, this might limit the comparability of the findings in different places.

\section{Conclusion}

This study found the majority of the respondents had poor knowledge about cervical cancer prevention measures. The majority of the study participants had favorable attitudes regarding cervical cancer prevention. Living in rural areas, not attending any formal education low income and having less than four children was negatively associated with respondents' knowledge towards cervical cancer prevention measures. There is needed to scale up cervical cancer prevention measures and services so that more women can access them irrespective of where they reside. Awareness creation campaigns should be held to provide comprehensive information about cervical cancer prevention and control mechanisms to women in all areas.

\section{Abbreviations}

HPV: Human Papilloma Virus, KAP:Knowledge, Attitude and Practice, SD:Standard deviation, VIA:Visual Inspection of the Cervix with Acetic Acid, SPSS:Statistical Package for Social Science, WHO:World Health Organization

\section{Declarations}

\section{Ethics Approval and Consent to Participate}

This study was approved by the research evaluation and an ethical review committee of Debre Tabor University College of Health Sciences, the use verbal consent was approved by the research evaluation and an ethical review committee since the procedure has no any negative health impact on the study participants and there is no sensitive issues / critical issues with the norm and culture of the community in the study area and finally informed verbal consent was obtained from all respondents.

\section{Consent for Publication}

Not Applicable

\section{Availability of Data and Material}

The datasets are available from the corresponding author. 


\section{Competing Interests}

We, the authors declare that we did not have competing interests.

\section{Funding}

The authors have no support or funding to report.

\section{Authors' Contributions}

TY Contributed to inception, design, analysis, interpretation, drafting of a research manuscript and final approval of the manuscript for publication. TJ Contributed to design, analysis, draft the manuscript and approval of the manuscript for publication. TD Contributed to design, supervise data collection process, analysis, interpretation, drafting of a research manuscript and final approval of the revised manuscript for publication. AM Contributed to the training of data collectors design and drafting of a research manuscript and final approval of the manuscript for publication.

\section{Acknowledgments}

We are very grateful to the Debre Tabor University for the approval of the Ethical Clearance. We express our heartfelt thanks to participants for their willingness to participate in the study. Our thanks also extend to the South Gondar health department for their cooperation and assistance during data collection.

\section{Authors' Information}

Yilkal Tafere Gualie : Assistant professor of Epidemiology

Email: yilkal2007@gmail.com

Tezera Jemere Aragaw: Lecturer of Pharmacology

Email: tezeraadis1982@gmail.com

Tsion Desalegn Jember: Lecture of General public health

Email: tsi_des@yahoo.com

Addisu Melak Bayafers: Lecturer of Biochemistry

AM: addismelak@gmail.com

\section{References}

1. Okonufua, "HPV vaccine and prevention of cervical cancer in Africa". African Journal Reproductive Health;2007;11:7-1 
2. (2008). HPV Information Centre. Human Pappiloma Virus and Related Cancers Summary Report Update. Third edition, 2008.

3. P. Armstrong, Journal of Managed Care Pharmacy, 2010; 16 (3): 217-30. Australian Institute of Health and Welfare (AlHW), Australasian Association of Cancer Registries (AACR). Cancer in Australia: An Overview. Cancer series no. 46. Cat. no. CAN 42. Canberra

4. J. Snijders, R.D. Steenbergen, D.A. Heideman, C.J. Meijer. HPV-Medicated Cervical Carcinogenesis: Concepts and Clinical Implication. J Pathol 2006;208:152-64.

5. Anorlu RI (2008) Cervical cancer: The sub-Saharan African perspectve. Reprod Health Maters 16: 419

6. WHO/ICO (2009) Human papilloma virus and related cancers in Ethiopia

7. Tebeu PM, Major AL, Rapiti E, et al. The attitude and knowledge of cervical cancer by Cameroonian women; a clinical survey conducted in Maroua, the capital of Far North Province of Cameroon. Int $\mathrm{J}$ Gynecol Cancer. 2008 Jul-Aug;18(4):761-5

8. Ajayi IO, Adewole IF: Knowledge and attitude of general outpatient attendants in Nigeria to cervical cancer. Cent Afr J Med. 1998 Feb;44(2):41-3

9. Mukama et al. :women's knowledge and attitudes towards cervical cancer prevention: a cross sectional study in eastern Uganda, BMC Women's Health (2017) 17:9 DOI 10.1186/s12905-017-03653

10. Gichangi P., Estambale B., Bwayo J., Rogo K., Ojwang S., Opiyo A., Temmerman M.:Knowledge and practice about cervical cancer and Pap smear testing among patients at Kenyata National Hospital, Nairobi, Kenya; Int. J. Gynecologic Cancer 2003,13(6):827-33. )

11. Mulatu K, Motma A, Seid M, etal. Assessment of Knowledge, Attitude and Practice on Cervical Cancer Screening among Female Students of Mizan Tepi University, Ethiopia, 2016. Cancer Biol Ther Oncol.2017, 1:1.)

12. F. Adewole, J. Benedet, (2005). "Evolving a strategic approach to cervical cancer control in Afri ca."Gynecologic Oncology 2005; 99(3): 209-212

13. Adanu RM Cervical cancer knowledge and screening in Accra, Ghana. J Wom Health Gend Base Med 2002, 11: 487-488

14. Eaker S, Adami HO, and Sparen P. Attitudes to screening for cervical cancer: a population based study in Sweden. Cancer Causes and control 2001 Aug; 12(6):519-28.

\section{Tables}

Table 1: The socio-demographic characteristics of women in selected districts of south Gondar zone Amhara region, north-central Ethiopia, 2019(N=844) 


\begin{tabular}{|c|c|c|}
\hline Variables & Frequ & ency \\
\hline Religion & No & $(\%)$ \\
\hline Orthodox & 808 & 95.7 \\
\hline Muslim & 36 & 4.3 \\
\hline \multicolumn{3}{|l|}{ Educational status } \\
\hline Not attend any formal education & 345 & 40.9 \\
\hline Primary & 499 & 59.1 \\
\hline \multicolumn{3}{|l|}{ Occupation of the respondent } \\
\hline Housewife & 367 & 43.5 \\
\hline Farmer & 166 & 19.7 \\
\hline Government employee & 160 & 19 \\
\hline Other* & 151 & 17.9 \\
\hline \multicolumn{3}{|l|}{ Marital status } \\
\hline Single & 146 & 17.3 \\
\hline Married & 618 & 73.2 \\
\hline Divorced & 57 & 6.8 \\
\hline Widowed & 23 & 2.7 \\
\hline \multicolumn{3}{|l|}{ Resident } \\
\hline Rural & 514 & 60.1 \\
\hline Urban & 330 & 30.9 \\
\hline \multicolumn{3}{|l|}{ Family average monthly Income } \\
\hline$<=1000$ & 150 & 19.8 \\
\hline $1001-2000$ & 378 & 49.9 \\
\hline$>2000$ & 230 & 30.3 \\
\hline
\end{tabular}

*Other includes student, daily laborer merchant

Table 2 : Knowledge women about cervical cancer and its preventive measures, in Selected districts of South Gondar zone, Amhara region North central Ethiopia,2019 ( $N=844)$ 


\begin{tabular}{|c|c|c|c|}
\hline & Variables & No & $\%$ \\
\hline 1 & Have you ever heard about cervical cancer? & & \\
\hline & Yes & 557 & 66 \\
\hline & No & 287 & 40 \\
\hline 2. & Cervical cancer is curable if detected early & & \\
\hline & Yes & 89 & 10.5 \\
\hline & No & 755 & 89.5 \\
\hline 3 & Early detection of cervical cancer is helpful in its treatment & & \\
\hline & Yes & 120 & 14.2 \\
\hline & No & 724 & 85.8 \\
\hline 4 & Knew at least one risk factor for cervical cancer & & \\
\hline & Yes & 238 & 28.2 \\
\hline & No & 606 & 71.8 \\
\hline 5 & Someone can be vaccinated against cervical cancer & & \\
\hline & Yes & 80 & 1 \\
\hline & No & 604 & 99 \\
\hline 6 & Knew at least one preventive measure for cervical cancer & & \\
\hline & Yes & 250 & 29.6 \\
\hline & No & 594 & 70.4 \\
\hline 7 & Knew at least one symptom of cervical cancer & & \\
\hline & Yes & 150 & 17.8 \\
\hline & No & 694 & 82.2 \\
\hline 8 & Over all Knowledge about cervical cancer prevention measures & & \\
\hline & Yes & 212 & 25.12 \\
\hline & No & 632 & 74.88 \\
\hline
\end{tabular}

Table 3 : Attitudes of women about cervical cancer and its preventive measures, in Selected districts of South Gondar zone, Amhara region North central Ethiopia,2019 ( $N=844)$ 


\begin{tabular}{|c|c|c|c|c|c|}
\hline \multirow[t]{2}{*}{ No. } & \multirow[t]{2}{*}{ Variables } & \multicolumn{2}{|c|}{ Disagree } & \multicolumn{2}{|c|}{ Agree } \\
\hline & & No & $\%$ & No & $\%$ \\
\hline 1 & $\begin{array}{l}\text { Carcinoma of the cervix is highly prevalent in our country and is } \\
\text { a leading cause of deaths amongst all malignancies in Ethiopia }\end{array}$ & 447 & 51.9 & 441 & 48.1 \\
\hline 2 & Any adult woman including you can acquire cervical cancer & 403 & 49.9 & 431 & 50.1 \\
\hline 3 & $\begin{array}{l}\text { Carcinoma of the cervix cannot be transmitted from one person } \\
\text { to another }\end{array}$ & 322 & 38.2 & 522 & 61.8 \\
\hline 4 & Screening helps in prevention of carcinoma of the cervix & 237 & 28.1 & 607 & 71.9 \\
\hline 5 & Screening causes no harm to the client & 300 & 35.5 & 544 & 64.5 \\
\hline 6 & Screening for premalignant cervical lesions is not expensive & 372 & 40.1 & 472 & 59.9 \\
\hline 7 & If screening is free and causes no harm, will you screen & 79 & 9.4 & 765 & 90.6 \\
\hline
\end{tabular}

Table 4: predictors of knowledge of women towards cervical cancer prevention measures in selected districts of South Gondar zone, Amhara region; north central Ethiopia; 2019.

\begin{tabular}{|c|c|c|c|c|}
\hline \multirow[t]{2}{*}{ Variables } & \multicolumn{2}{|c|}{ Knowledge score } & \multirow[t]{2}{*}{$\operatorname{coR}(95 \% \mathrm{Cl})$} & \multirow[t]{2}{*}{$\operatorname{AOR}(95 \% \mathrm{Cl})$} \\
\hline & Good & Poor & & \\
\hline \multicolumn{5}{|l|}{ Place of Resident } \\
\hline Rural & 80 & 506 & 1 & 1 \\
\hline Urban & 132 & 198 & $0.24(.21, .5 .3)$ & $0.21(.18, .34) * \star$ \\
\hline \multicolumn{5}{|l|}{ Level of education } \\
\hline Not attend formal education & 67 & 287 & $0.56(.2, .8)$ & $0.5(.3, .75)^{\star \star}$ \\
\hline Attend formal education & 145 & 354 & 1 & 1 \\
\hline \multicolumn{5}{|l|}{ Monthly household income } \\
\hline$<=2000$ & 152 & 406 & $0.6(.4, .82)$ & $0.57(.43, .81)^{\star \star}$ \\
\hline$>2000$ & 90 & 140 & 1 & 1 \\
\hline Yes & 100 & 50 & $3.83(2.1,5.7)$ & $3.6(2.5,4.6)^{\star \star}$ \\
\hline No & 112 & 520 & 1 & 1 \\
\hline \multicolumn{5}{|l|}{ Parity } \\
\hline $0-4$ & 172 & 528 & $0.87(.5, .93)$ & $0.8(.6, .86)^{\star \star}$ \\
\hline$>4$ & 40 & 107 & 1 & 1 \\
\hline
\end{tabular}


** Significantly associated $\mathrm{P}<0.05$

Page 14/14 